\title{
CONDITIONAL OPTIMIZATION MATHEMATICAL MODEL OF THE ASPHALT CONCRETE MIXTURE GRADING
}

\author{
Henrikas Sivilevičius', Valentinas Podviezko² \\ 'Dept of Transport Technology Equipment, Vilnius Gediminas Technical University, Lithuania \\ E-mail:henrikas@ti.vtu.lt,Fax:(370-2) 31-56-0122Dept of Mathematical Statistics, \\ Vilnius Gediminas Technical University, Lithuania.E-mail:Isaulis@rasa.vtu.lt
}

Received 09 Sept 2001; accepted 05 Febr 2001

\begin{abstract}
A new partial conditional optimization method which enables to select the best ratio of imported fillers not only while designing the composition of asphalt concrete mixture but also while adjusting the composition of the produced asphalt concrete mixture according to the actual quality of hot fractions is presented.

The constructed mathematical model, algorithm and the solved task prove that irrespective of the number of fillers (from 2 to 7 and more) the ratio of their mass can be selected which enables to produce an asphalt concrete mixture which meets the requirements of the composition project best. The mass ratio $\lambda$ of imported fillers $A_{1}$ and reclaimed dust $A_{2}$, which settled and accumulated in the dry purification equipment of an asphalt concrete plant presented in Regulations DAT.AD-96 was taken into account for the first time.

Methodological scientific novelty and a possibility to apply it in practice can improve the control of asphalt concrete mixture production.
\end{abstract}

Keywords: asphalt concrete mixture, asphalt plant, calculation grading, optimization, mathematical model.

\section{Introduction}

To produce asphalt concrete mixture of the set mark according to properties identified by laboratory tests of aggregates and organic binder, the mass ratio, which produces the best physical and mechanical indices of the designed mixture, which comply with the requirements of norm [1] is selected. The curve of grading of designed asphalt concrete mineral aggregate obtained from those indices shall be smooth and shall pass between (preferably through the median) of the normalized curves of the selected type of asphalt concrete mixture. The optimum bitumen content is first calculated according to the bitumen capacity (absorption) [2,3] or other approximate formulae. Then it is specified by experiments having prepared and tested 3-5 portions of asphalt concrete mixture $[4,5]$ of the same grading but with a different binder content.

The bitumen content of a series of samples tested in a laboratory which have the best properties of asphalt concrete mixture is considered optimum and is recommended to be used when producing asphalt concrete mixture in an asphalt plant. Such method of selecting the grading of asphalt concrete mixture is suitable only during the designing process, but not when it is produced.

To select the ratio of aggregates which compose an asphalt concrete mixture, several mathematical methods which are based on various principles were constructed a few decades ago or have just been constructed [6-12, 3]. It proves that it is not easy to select the optimum grading of an asphalt concrete mixture and is not an onefaceted problem.

The grading of the mixture designed in a laboratory shall be precisely 'carried out' when producing it in an asphalt plant. With regard to 15 models of 99 asphalt concrete plants operating in Lithuania of various efficiency, structure, the scheme of mixture production technology, the type of fuel used, servicable life as well as other factors, we could consider that the quality of asphalt concrete mixture production varies and different methods are required to effectively manage it.

Most of operating asphalt concrete plants produce the hot asphalt concrete mixture of various types according to the traditional technology $[13,14]$. The essence of this technology is that the asphalt concrete mixture content is made up not of initial cold aggregates accumulated in the stacks of the asphalt concrete mixture in the plant territory but of hot mineral materials of individual 3-5 fractions of discrete batched portions technologically screened in the asphalt plant.

If the quality of asphalt plants is very high, dry dust is segregated and accumulated from dry and heated aggregates flow during the technological process of mixture production in the batcher of air purification equip- 
ment. The effectiveness of dust segregation depends on the equipment construction, work regime, technical condition and grading of materials [15]. Segregated dust from air flow and accumulated in a batcher (reclaimed dust, $\mathrm{RD}$ ) can be used to produce asphalt concrete mixture by identifying ratio $\lambda$ of imported fillers (IF) and their batches. If ratio $\lambda$ of aggregates mass is not specified, all models of the same grading which had been constructed before make it possible to use only one material which does not comply with the requirements of asphalt concrete mixture technology.

When the reclaimed dust settles in the bin and is batched, it can have one of the three input balances. First, more dust settles than it is used; second, the settled content is used; and third, less dust settles than it is used. Such mass balances change very often during one work shift by transferring from one level to another due to the change of initial cold aggregates grading as well as due to the stochastic origin of parameters of production technological operations carried out in an asphalt plant. The change of balance levels enables the operator of an asphalt plant to change not only the ratio of IF and $R D$ but also the mass of hot fraction batches.

When solving the task of material mass selection, various mathematical models of simulating the mixture composition can be used. For instance, the general model [3] would be suitable for that; however linear relation shall be set up between IF and RD and this relation shall be inserted as an additional condition. The analysis of asphalt concrete production technology gave grounds to assess the selected ratio $\lambda$ in practice for the first time. In our research, an original evaluation algorithm of required technological ratio of IF to $R D$ is presented.

The research aims to construct the conditional optimization mathematical model of finally batched constituent aggregates mass ratio of the produced asphalt concrete mixture grading, when the grading of screened hot fractions, cold IF and RD is known and any technological ratio $\lambda$ of the fine disperse materials mentioned above is selected. The insertion of this ratio $\lambda$ as an additional condition is called 'conditional' optimization. Having this model, calculation algorithm and software, during each work shift such finally batched constituent aggregates mass ratio can be selected precisely and immediately from screened hot fraction grading effective control data in an asphalt plant due to which grading of asphalt concrete mixture complies with the requirements stipulated in Regulations DAT.AD-96 and the project.

\section{The causes of instability of finally discretely batched aggregates grading}

Hot fractions grading and their contamination with particles of adjacent fractions depend on the construction of an asphalt concrete plant screen, grading of dried and heated mineral mixture distributed through technological screens and the delivered unit per time unit of this mixture which settles on the screen, ie actual effi- ciency of cold and hot elevators $[16,17]$. When the amplitude of fluctuations of the screened hot aggregate mixture grading and loading of technological screens with this mixture is very wide, particles of various sizes are screened from the hot bin sections of asphalt plant (Fig 1), contamination of which during the work shift and between shifts changes considerably.

Guidelines of Asphalt Concrete Production Process DI-04 in Civil Engineering Regulations [18] are not complete since the actual grading of hot fractions screened through different technological screens in an asphalt concrete plant is not taken into consideration. This document shows how to estimate the obtained content of hot fractions from the curve of grading of asphalt concrete mixture aggregate designed in a laboratory. Here only approximate difference of technological and laboratory screens mesh sizes are indirectly taken into consideration by comparing the size of technological screen with the size of particles passing through its mesh. The guidelines stipulate that hot fractions are contaminated with finer particles than required; however, data about such contamination are not given. Following the presented methodology and sample calculation, possible quantity in per cent of hot fractions obtained through screening can be estimated approximately (not required for batching), the usage of which enables to estimate the initial values of fixed positions determined by discrete batches of those fractions.

\section{Asphalt concrete aggregates, mineral elements and their labelling}

Asphalt concrete and its mixture are made up of aggregates and organic materials. Aggregates have certain grading defined as partial residue on laboratory screens, full fractions on laboratory screens or cumulative residue through those screens in per cent. Those who draw up normative documents, designers of asphalt concrete mixture composition, technologists of its production or quality controllers shall decide which of the three characteristics of grading shall be used with regard to traditions and aims.

Each aggregate is composed of the whole complex of both polished and (or) unpolished particles classified into narrow fractions according to the size of laboratory screen mesh. One or several adjacent narrow fractions make up the mineral element of an aggregate. Following the theory of asphalt concrete structure, its mineral part is always made up of two mineral components: mineral fillers (grains): less than $0.09 \mathrm{~mm}$ or $0.071 \mathrm{~mm}$, and sandgrains with a diameter of 2-0.09 $\mathrm{mm}$ or $5-0.071 \mathrm{~mm}$. The structure of asphalt concrete is often formed by the third mineral element: crushed stone (grains less than 2 or $5 \mathrm{~mm}$ ). These two or three mineral elements make up not only asphalt concrete and its mixture but aggregates as well. Therefore, terms 'aggregates' and 'mineral element' are not synonyms since they define different products in terms of their quality. Taking that into consider- 
ation, it could be stated that asphalt concrete mixture or any other aggregate $j(j=1, \ldots, m)$ is made of $k$ mineral elements $(i=1, \ldots, k)$. In most cases, $k$ is 2 or 3 . To evaluate their quality by using the whole grading, the number of laboratory screens with a bottom corresponds to the mineral elements. Therefore, aggregates in an asphalt concrete mixture are its constituent parts and mineral elements are its additional parts. It is only bitumen which is both a material (when not added to aggregates) and an element (when added to aggregates and is in the produced or to be produced asphalt concrete mixture).

Since cold activated or inactivated IF are used in any type of asphalt concrete mixture, it is reasonable to apply index $A_{1}$ to them (Fig 1).

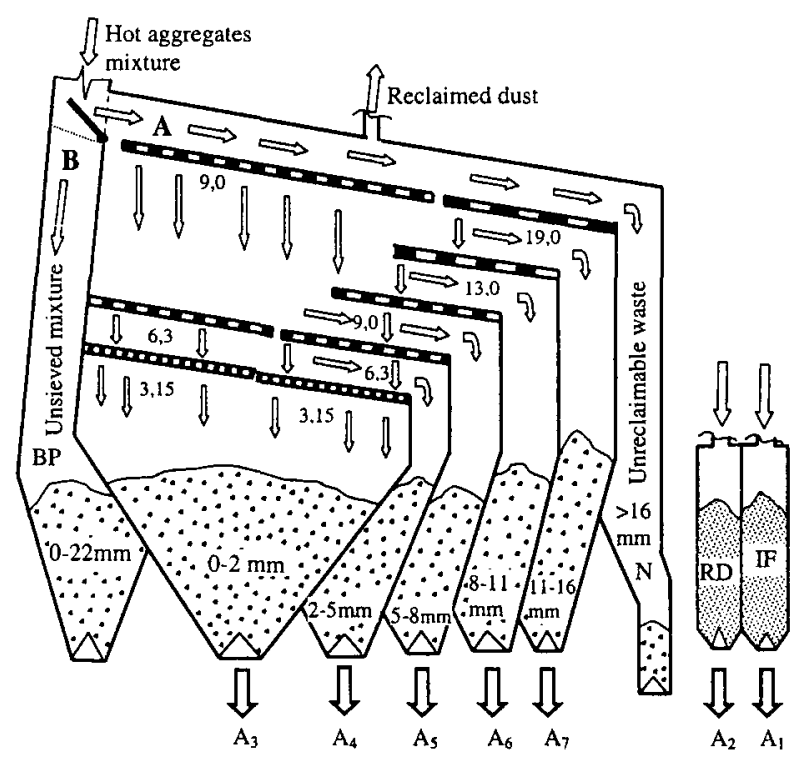

Fig 1. The circuit of technological screens of the screen of asphalt mixing plant TELTOMAT-160 and its multisection hopper, containing discretely finally dozen screened hot fractions, and also hoppers of cold RD and IF
The $\mathrm{RD}$ is accumulated only in asphalt plants with air and gas dry cleaning from dust as well as equipment necessary to store and batch it. (Teltomat-5, Teltomat160, Ammann Euro A 240, ir 160 Global H, Marini, etc.). It is marked as index $A_{2}$.

When asphalt concrete mixture of any type is produced, the finest hot fraction $0-2 \mathrm{~mm}$ screened through technological screens is always used. Therefore, it shall be marked as $A_{3}$.

When batching all hot fractions in the common weight batcher following the principle of adding their masses, the adjacent coarser hot fraction is added to the finest fraction $A_{3}$; therefore, it is purposeful to mark it $A_{4}$ (hot fraction of $2-5 \mathrm{~mm}$ ). If the third material is used to produce asphalt concrete mixture $(5-8 \mathrm{~mm})$ which is coarser than the finest or the second by its size, it is marked $A_{5}$. With regard to the permitted diameter of the coarsest particles of the produced asphalt concrete mixture and the number of technological screens of asphalt concrete plant sifter (the number of obtained hot fractions), the fourth hot fraction can be obtained and used (8-11 mm) $A_{6}$ and the last fifth hot fraction (11$16 \mathrm{~mm}) A_{7}$.

\section{Mathematical model of asphalt concrete aggregates optimum mass ratio}

The task is solved in practice, when the required type of an asphalt concrete mixture of optimum composition which complies to the composition stipulated in Regulations DAT.AD-96 with regard to the used production technology shall be produced from aggregates $j$, taking into consideration their actual grading.

Grading of all $j$ aggregates is known from laboratory research, ie their partial sieve residue particles in unit parts (could be in per cent) $a_{i j}$ on laboratory screen $i(i=1, \ldots, k)$ (Table 1$)$.

These data are identified in the laboratory of an asphalt concrete plant periodically or when the parameters of the technological process of production changes (when the composition of an asphalt concrete mixture to

Table 1. The summary of aggregates partial residues on laboratory screens mass estimates

\begin{tabular}{|c|c|c|c|c|c|c|c|}
\hline \multirow{2}{*}{$\begin{array}{l}\text { The length of the } \\
\text { side of square mesh } \\
\text { of laboratory screen } \\
d_{i} \text { mm } i=1, \ldots, k\end{array}$} & \multirow[t]{2}{*}{$\begin{array}{l}\text { Mineral } \\
\text { element }\end{array}$} & \multicolumn{5}{|c|}{$\begin{array}{l}\text { Partial sieve residues of aggregate } A_{j} \quad(j=1, \ldots, m) \\
\qquad a_{i j}(i=1, \ldots, k)\end{array}$} & \multirow{2}{*}{$\begin{array}{l}\text { Partial sieve } \\
\text { residues of } \\
\text { standard mixture } \\
a_{i 0} \\
\end{array}$} \\
\hline & & $A_{1}$ & $A_{2}$ & $A_{3}$ & $\ldots \ldots$ & $A_{m}$ & \\
\hline$d_{1}$ & \multirow{2}{*}{$\begin{array}{c}\text { Crushed } \\
\text { stone }(>2 \\
\mathrm{mm})\end{array}$} & $a_{11}$ & $a_{12}$ & $a_{13}$ & $\ldots \ldots$ & $a_{1 m}$ & $a_{10}$ \\
\hline$d_{2}$ & & $a_{21}$ & $a_{22}$ & $a_{23}$ & $\ldots \ldots$ & $a_{2 m}$ & $a_{20}$ \\
\hline$d_{3}$ & \multirow{2}{*}{$\begin{array}{c}\text { Sand } \\
(2-0,09 \\
\mathrm{mm})\end{array}$} & $a_{31}$ & $a_{32}$ & $a_{33}$ & $\ldots \ldots$ & $a_{3 m}$ & $a_{30}$ \\
\hline$\vdots$ & & $\vdots$ & $\vdots$ & $\vdots$ & $\ldots \ldots$ & $\vdots$ & $\vdots$ \\
\hline$d_{k}$ & \multirow{2}{*}{$\begin{array}{c}\text { Mineral } \\
\text { fillers } \\
(<0,09 \mathrm{~mm})\end{array}$} & $a_{k 1}$ & $a_{k 2}$ & $a_{k 3}$ & $\ldots \ldots$ & $a_{k m}$ & $a_{k 0}$ \\
\hline Bottom & & $f_{1}$ & $f_{2}$ & $f_{3}$ & ....... & $f_{m}$ & $f_{0}$ \\
\hline
\end{tabular}


be produced is changed or when the grading of its constituent aggregates changes).

In most cases, asphalt concrete mixture production technology and the methodology of its composition design is based on the condition that:

1) the sum of all aggregate mass $A_{j}$ equals one (or $100 \%$ ), and the quantity of bitumen is calculated in per cent: $100 \%$ or parts of unit more than one:

$$
\sum_{j=1}^{m} A_{j}=1
$$

2) the total mass $f_{0}$ of particles of the size less than $0.09 \mathrm{~mm}$ in the whole designed mixture is known (presented in a designing task):

$$
\sum_{j=1}^{m} A_{j} f_{j}=f_{0}
$$

$f_{j}$ is mass of particles less than $0.09 \mathrm{~mm}$ in aggregate $j$ in parts of unit (or per cent).

The total partial sieve residue $Z_{i}$ of the designed asphalt concrete mixture is made up of all aggregates $m$ partial sieve residues on $i$ laboratory screen

$$
Z_{i}=\sum_{j=1}^{m} A_{j} a_{i j}, \quad i=1, \ldots, k .
$$

Partial sieve residues $a_{i 0}$ of the designed type of asphalt concrete mixture grading normative curve on $i$ laboratory sieve are known from normative documents, for example, Regulations DAT.AD-96.

When using conditions (1)-(2), differences $W_{i}$ [5] of calculated $Z_{i}$ and normative $a_{i 0}$ partial sieve residues can be expressed:

$$
\begin{gathered}
W_{i}=Z_{i}-a_{i 0}=\sum_{j=3}^{m} A_{j} \beta_{i j}-\beta_{i 0}, \\
\beta_{i j}=a_{i j}-\frac{K_{j}}{K_{2}} a_{i 2}-\left(1-\frac{K_{j}}{K_{2}}\right) a_{i 1}, \\
\beta_{i 0}=a_{i 0}-\frac{K_{0}}{K_{2}} a_{i 2}-\left(1-\frac{K_{0}}{K_{2}}\right) a_{i 1}, \\
K_{j}=1-\frac{f_{j}}{f_{1}}, j=3, \ldots, m \text { ir } j=0, i=1, \ldots, k .
\end{gathered}
$$

When reducing (minimising) the sum $\sum_{i=1}^{k} W_{i}^{2}$ of quadratic partial sieve residues $W_{i}$ and using the method of smallest squares for all laboratory screens and by comparing partial derivatives of the sum $\sum_{i=1}^{k} W_{i}^{2}$ with respect to all constituent aggregates $A_{j}$ to zero $(j=3, \ldots, m)$, the following is obtained:

$$
\frac{\partial\left(\sum_{i=1}^{k} W_{i}^{2}\right)}{\partial A_{j}}=\frac{\partial\left(\sum_{i=1}^{k}\left(\sum_{j=3}^{m} A_{j} \beta_{i j}-\beta_{i 0}\right)^{2}\right)}{\partial A_{j}}=0
$$

or

$$
\sum_{i=1}^{k} \beta_{i l} \sum_{j=3}^{m} \beta_{i j} A_{j}=\sum_{i=1}^{k} \beta_{i l} \beta_{i 0}, \quad l=3, \ldots, m .
$$

Matrix [C] of system (4) is symmetric $[C] \cdot[A]=[D]:$

$$
[C]=\left(\begin{array}{cccc}
\sum_{i=1}^{k} \beta_{i 3}^{2} & \sum_{i=1}^{k} \beta_{i 3} \beta_{i 4} & \cdots & \sum_{i=1}^{k} \beta_{i 3} \beta_{i m} \\
\sum_{i=1}^{k} \beta_{i 4} \beta_{i 3} & \sum_{i=1}^{k} \beta_{i 4}^{2} & \ldots & \sum_{i=1}^{k} \beta_{i 4} \beta_{i m} \\
\ldots & \cdots & \cdots & \cdots \\
\sum_{i=1}^{k} \beta_{i m} \beta_{i 3} & \sum_{i=1}^{k} \beta_{i m} \beta_{i 4} & \cdots & \sum_{i=1}^{k} \beta_{i m}^{2}
\end{array}\right)
$$

and

$$
[\boldsymbol{D}]=\left(\begin{array}{llll}
\sum_{i=1}^{k} \beta_{i 0} \beta_{i 3} & \sum_{i=1}^{k} \beta_{i 0} \beta_{i 4} & \cdots & \sum_{i=1}^{k} \beta_{i 0} \beta_{i m}
\end{array}\right)^{T} .
$$

Having solved system (4), we will obtain values $A_{3}, \ldots, A_{m}$, and the values of other $A_{1}$ and $A_{2}$ will be obtained from conditions (1) and (2).

Calculation algorithm would be as follows:

1. We take two from $f_{j} \neq 0,\left(f_{1} \neq 0\right.$ and $\left.f_{2} \neq 0\right)$;

2. We calculate $K_{j}=1-\frac{f_{j}}{f_{1}}(j=2, \ldots, m)$ as well;

3. We calculate $\frac{K_{j}}{K_{2}}$ and $1-\frac{K_{j}}{K_{2}}(j=3, \ldots, m)$;

4. We calculate

$$
\beta_{i j}=a_{i j}-\frac{K_{j}}{K_{2}} a_{i 2}-\left(1-\frac{K_{j}}{K_{2}}\right) \cdot a_{i 1}, \quad(j=3, \ldots, m)
$$

and construct matrices $[B]=\left\|\beta_{i j}\right\|$ and $\left[B_{0}\right]=\left\|\beta_{i 0}\right\|$, $(i=1, \ldots, k ; j=3, \ldots, m)$;

5. We construct the system of linear equations $[C] \cdot[A]=[D] ;$ here $[C]=\left[B^{T}\right][B], \quad[D]=\left[B^{T}\right]\left[B_{0}\right]$, $[A]=\left[A_{3}, A_{4}, \ldots, A_{m}\right]^{T}$;

6. Having solved the system we obtain $A_{3}, \ldots, A_{m}$;

7. We calculate

$$
A_{2}=\frac{K_{0}}{K_{2}}-\frac{1}{K_{2}} \sum_{j=3}^{m} A_{j} K_{j}
$$

and

$$
A_{1}=1-\sum_{j=2}^{m} A_{j}
$$




\begin{tabular}{|c|c|c|c|c|c|c|c|c|c|c|c|c|c|c|}
\hline \multirow{3}{*}{\multicolumn{2}{|c|}{ 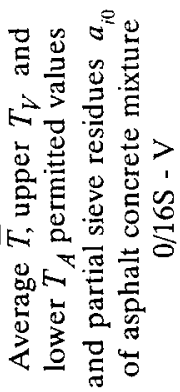 }} & $\vec{a}$ & $t_{1}^{\pi}$ & $\stackrel{8}{\circ}$ & $\begin{array}{l}8 \\
\text { த } \\
8\end{array}$ & $\vec{i}$ & $\begin{array}{l}8 \\
8 \\
1 \\
2\end{array}$ & $\begin{array}{l}8 \\
\text { రิ }\end{array}$ & $\begin{array}{l}m \\
\stackrel{m}{b}\end{array}$ & 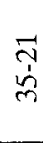 & $\overline{3}$ & 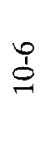 & ' & 1 \\
\hline & & $\vec{a}$ & It & $\stackrel{8}{8}$ & $n$ & $\stackrel{\infty}{2}$ & $\sqrt{6}$ & in & F & $\stackrel{\infty}{\sim}$ & $\stackrel{\infty}{\rightarrow}$ & $\infty$ & ' & ' \\
\hline & & $\overrightarrow{0}$ & $0^{2}$ & 0 & $n$ & \pm & $\stackrel{n}{\varrho}$ & $\cong$ & $\stackrel{\circ}{-}$ & 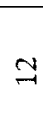 & $\stackrel{\varrho}{0}$ & $\stackrel{\varrho}{\circ}$ & $\begin{array}{l}0 \\
11 \\
4^{\infty}\end{array}$ & 8 \\
\hline \multirow{14}{*}{ 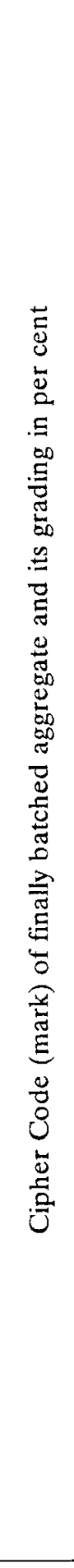 } & \multirow{2}{*}{ 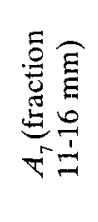 } & $\ddot{2}$ & & $\vec{\alpha}$ & $\hat{a}$ & $\infty^{m}$ & $\stackrel{m}{\sim}$ & $=$ & $\stackrel{2}{0}$ & 0 & 0 & 0 & ' & ' \\
\hline & & $\vec{j}$ & 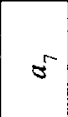 & $\hat{\theta}$ & $\stackrel{\nabla_{n}}{-}$ & $\stackrel{\sigma_{n}}{\sigma}$ & $\stackrel{\theta}{\theta}$ & 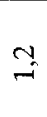 & o & ב̂ & 0 & 0 & $\begin{array}{l}0 \\
11 \\
4=\end{array}$ & $\underset{1}{8}$ \\
\hline & \multirow{2}{*}{ 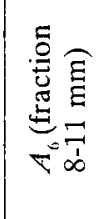 } & $\dot{a}$ & & $\stackrel{8}{ }$ & $\dot{\sigma}$ & बi & $\stackrel{m}{=}$ & rn & $\mathscr{O}_{0}^{\circ}$ & $\overrightarrow{0}$ & 0 & 0 & & ' \\
\hline & & $\overrightarrow{0}$ & $0^{\circ}$ & 0 & $\ddot{b}_{0}$ & \& & $\vec{\infty}$ & $\vec{\infty}$ & $\begin{array}{l}0 \\
\sim\end{array}$ & $\tilde{s}$ & $\overrightarrow{0}$ & 0 & $\begin{array}{l}0 \\
11 \\
40\end{array}$ & $\stackrel{8}{9}$ \\
\hline & \multirow{2}{*}{ 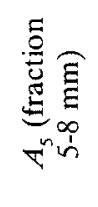 } & $\vec{D}$ & & $\stackrel{్}{\varrho}$ & 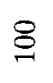 & 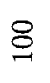 & $\overrightarrow{6}$ & $\begin{array}{l}b \\
\stackrel{-}{-1}\end{array}$ & $\underset{f}{0}$ & ? & 0 & 0 & ' & ' \\
\hline & & $\vec{j}$ & $0^{n}$ & 0 & 0 & 0 & ले & $\tilde{\infty}$ & $\stackrel{b}{\infty}$ & $\hat{m}$ & 3 & 0 & $\begin{array}{l}0 \\
11 \\
4\end{array}$ & § \\
\hline & \multirow{2}{*}{ 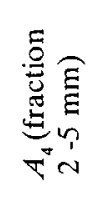 } & $\stackrel{\dot{a}}{\dot{a}}$ & & $\stackrel{8}{8}$ & $\stackrel{8}{\varrho}$ & $\stackrel{8}{\circ}$ & $\hat{a}$ & 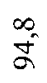 & $\stackrel{\stackrel{N}{ \pm}}{=}$ & $\stackrel{\infty}{\infty}$ & $\overrightarrow{0}$ & 0 & ' & ' \\
\hline & & $\dot{j}$ & $0^{\sigma}$ & 0 & 0 & 0 & $3_{0}^{\prime}$ & $\ddot{\forall}$ & $\begin{array}{l}0 \\
\infty \\
\infty\end{array}$ & $\stackrel{+}{=}$ & $\bar{i}$ & $\overrightarrow{0}$ & $\begin{array}{l}0 \\
11 \\
4^{*}\end{array}$ & 8 \\
\hline & \multirow{2}{*}{ 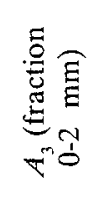 } & $\dot{\Delta}$ & & 8 & 8 & $\stackrel{8}{8}$ & $\stackrel{8}{\varrho}$ & $\stackrel{+}{\sigma}$ & $\frac{n}{3}$ & î & $\begin{array}{l}\vec{p} \\
\vec{n}\end{array}$ & $\dddot{3}$ & I & ' \\
\hline & & $\overrightarrow{\overrightarrow{0}}$ & $\sigma^{m}$ & 0 & 0 & 0 & 0 & $\stackrel{0}{\circ}$ & $\stackrel{9}{r}$ & 2 & $\frac{n}{n}$ & 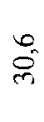 & $\begin{array}{l}m \\
\stackrel{m}{+} \\
\stackrel{m}{m}\end{array}$ & @ \\
\hline & \multirow{2}{*}{ 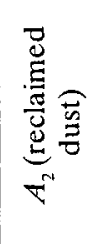 } & $\ddot{a}$ & & 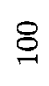 & $\stackrel{8}{ }$ & $\S$ & $\stackrel{8}{8}$ & $\stackrel{8}{\varrho}$ & 8 & gे & $\begin{array}{l}r \\
\infty \\
\infty\end{array}$ & ?n & . & 1 \\
\hline & & $\ddot{c}$ & $\sigma^{N}$ & 0 & 0 & 0 & 0 & 0 & 0 & b & $\underset{-}{-}$ & 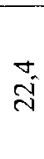 & $\frac{3}{2}$ & $\underset{-}{\mathcal{G}}$ \\
\hline & \multirow{2}{*}{ 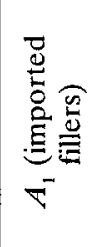 } & $\dot{\dot{i}}$ & & 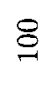 & $\Phi$ & $\S$ & $\underset{-1}{8}$ & $\S$ & 8 & $\S$ & $\frac{2}{2}$ & $\stackrel{\vec{\infty}}{\stackrel{\vec{\infty}}{2}}$ & . & 1 \\
\hline & & $\overrightarrow{0}$ & $\sigma^{-}$ & 0 & 0 & 0 & 0 & 0 & 0 & 0 & $\hat{0}$ & $\stackrel{\nabla}{ \pm}$ & $\begin{array}{l}g \\
\dot{D} \\
11 \\
-\end{array}$ & 8 \\
\hline \multicolumn{4}{|c|}{ 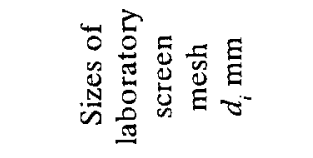 } & $\begin{array}{l}\vec{N} \\
\text { N }\end{array}$ & $\stackrel{0}{\circ}$ & $\stackrel{\sim}{=}$ & $\infty$ & in & $N$ & 5 & $\begin{array}{l}\text { ra } \\
\text { s. }\end{array}$ & $\stackrel{8}{0}$ & \begin{tabular}{l}
$\tilde{E}$ \\
\multirow{0}{0}{} \\
0 \\
0
\end{tabular} & $\underset{\sim}{\Xi}$ \\
\hline
\end{tabular}


Asphalt concrete mixture production technology presented in Requirements on Asphalt Concrete Mixtures [1] specifies the mass ratio of two batched finer disperse aggregates (reclaimed dust and imported filler), which can be expressed by the coefficient of proportion $\lambda$. If $A_{1}$ is a quantity of batched cold IF in the produced asphalt concrete mixture, and $A_{2}$ is a required quantity of batched $\mathrm{RD}$

$$
A_{1}=\lambda \cdot A_{2} .
$$

Following technological specifications presented in Regulations DAT.AD-96, the mass ratio of these fine disperse aggregates in a mixture of various types of asphalt concrete is

$$
1 \leq \lambda \leq 3 .
$$

Having taken that into consideration, the first two columns $A_{1}$ and $A_{2}$ shall be changed by one common column $\left(\overrightarrow{A_{1}}\right)$ in the initial table of data (Table 1 ). Those values which are obtained from the sum of two aggregates are marked by the line above the symbol of an estimate

$$
\begin{aligned}
& \overline{A_{1}}=A_{1}+A_{2}, \text { when } A_{1}=\lambda A_{2}, \text { i.e. } \\
& \lambda A_{2}+A_{2}=\overline{A_{1}} \text { or } A_{2}(\lambda+1)=\overline{A_{1}} .
\end{aligned}
$$

Values $\overline{a_{i 1}}$ of column $\overline{A_{1}}$ and relevant value $\overline{f_{1}}$ shall be estimated.

Then $a_{i 1} A_{1}+a_{i 2} A_{2}=\overline{a_{i 1}} \overline{A_{1}}$ and with the help of formulae (7)-(8) we obtain

$$
\overline{a_{i 1}}=\frac{a_{i 2}+\lambda a_{i 1}}{1+\lambda}
$$

By analogy

$$
\overline{f_{1}}=\frac{f_{2}+\lambda f_{1}}{1+\lambda}
$$

Value $\overline{f_{1}}$ can be estimated in a different way:

$$
\overline{f_{1}}=100-\sum_{i=1}^{k} \overline{a_{i 1}} .
$$

The results of calculations according to both formulae coincide

5. A sample of mathematical model application by adjusting the composition of mineral element of asphalt concrete mixture in an asphalt concrete plant

Asphalt concrete mixture is made of seven aggregates (five hot fractions $A_{3}, A_{4}, A_{5}, A_{6}, A_{7}$, reclaimed dust $A_{2}$ and imported fillers $A_{1}$ ), the grading of which is presented in Table 2 .

The solution of the task when the mass ratio of imported fillers and reclaimed dust is not identified was made for the following fractions in the scientific report [5]:
$A_{3}=0,3314 ; \quad A_{4}=0,1634 ; \quad A_{5}=0,1225 ;$ $A_{6}=0,1178 ; A_{7}=0,1926$. However, the required quantity $A_{2}$ of reclaimed dust, estimated according to (5) was negative (even though very small): $A_{2}=-0,0552$.

Therefore, we will solve this sample with the help of conditional (because we are taking into consideration additional condition $\lambda$ ) optimization methodology and by applying Maple-5 or Maple- 6 software package [19, 20], when different ratios $\lambda$ of imported fillers $A_{1}$ and reclaimed dust $A_{2}$, ie $\lambda=1,2,3$

Taking into consideration equations (9) and (10), we will estimate $\overline{a_{i 1}}$ and $f_{1}$ (Table 3 ).

Table 3. Narrow fractions lump $\bar{A}_{j}$ in percentage obtained by batching imported fillers and reclaimed dust

\begin{tabular}{|c|c|c|c|c|c|}
\hline $\begin{array}{c}\text { Labor- } \\
\text { atory } \\
\text { screen } \\
\text { No }\end{array}$ & $\begin{array}{c}\text { Partial sieve } \\
\text { residue on } \\
\text { laboratory screen, } \\
\%\end{array}$ & \multicolumn{2}{|c|}{$\begin{array}{c}\text { Particle mass } \\
\text { from imported fillers and } \\
\text { reclaimed dust \%, when ratio } \\
\lambda \text { is accepted }\end{array}$} \\
\hline$i$ & $A_{1}$ & $A_{2}$ & $\lambda=1$ & $\lambda=2$ & $\lambda=3$ \\
\hline $1-6$ & 0 & 0 & 0 & 0 & 0 \\
\hline 7 & 0 & 0,1 & 0,05 & 0,0333 & 0,025 \\
\hline 8 & 0,7 & 1,2 & 0,95 & 0,8676 & 0,825 \\
\hline 9 & 14,4 & 22,4 & 18,4 & 17,076 & 16,4 \\
\hline$f_{j}$ & 84,9 & 76,3 & 80,6 & 82,0 & 82,8 \\
\hline
\end{tabular}

Case $\lambda=1$ complies with the condition when $A_{1}=A_{2}$.

Particles of size from $22,4 \mathrm{~mm}(i=1)$ to $2 \mathrm{~mm}$ ( $i=6$ ) are absent in imported fillers $A_{1}$ and reclaimed dust $A_{2}$; therefore zeros are written in the first six line.

The following system of linear equations is obtained:

$$
\left\{\begin{array}{l}
7635,55 A_{4}+2929,87 A_{5}+2234,21 A_{6}+2065,47 A_{7}=2279,80 \\
2929,87 A_{4}+9664,16 A_{5}+3780,71 A_{6}+2920,62 A_{7}=2678,20 \\
2234,21 A_{4}+3780,71 A_{5}+9780,29 A_{6}+4001,50 A_{7}=2754,82 \\
2065,47 A_{4}+2920,62 A_{5}+4001,50 A_{6}+11021,53 A_{7}=3992,21 .
\end{array}\right.
$$

The solution of the system is as follows: $A_{4}=0,1925 ; A_{5}=0,1229 ; A_{6}=0,1177 ; A_{7}=0,1925$.

According to (5), $A_{3}=0,2906$ and according to (6) $\overline{A_{1}}=0,0837$, i e $A_{1}=A_{2}=0,0419$.

We have estimated quantities of all batched aggregates mass in unit parts when $\lambda=2$ and $\lambda=3$ is selected.

Findings are presented in Table 4 .

In Table 5 values of screened cumulative residues of the designed optimum grading asphalt concrete mixture when the selected ratio $\lambda$ of imported fillers and reclaimed dust is changed from 1...3. The graph (Fig 2) of the designed asphalt concrete mixture grading is constructed from them when $\lambda=1$, and it shows that having taken into consideration the actual grading of the used aggregates $A_{1}, \ldots, A_{7}$ it is optimum since it hardly differs from the normalized composition of wearing course of 
asphalt concrete $0 / 16 \mathrm{~S}-\mathrm{V}$. Values of the designed asphalt concrete mixture laboratorically screened cumulative residues are close to normalized values of relevant laboratory screens of the curve which divides tolerance field and is placed between the permitted upper $T_{v}$ and lower $T_{A}$ limits.

Table 4 . The optimum mass ratio of discretely batched aggregates, when 1 is changed

\begin{tabular}{|c|c|c|c|}
\hline $\begin{array}{c}\text { Mark of } \\
\text { aggregate }\end{array}$ & \multicolumn{3}{|c|}{$\begin{array}{r}\text { Selected mass ratio } \lambda \text { of imported fillers } \\
A_{1} \text { and reclamed dust } A_{2} \text { and the } \\
\text { corresponding ratio of all batches }\end{array}$} \\
\hline & $\lambda=1$ & $\lambda=2$ & $\bar{\lambda}=3$ \\
\hline$A_{1}$ & 0,08373 & 0,08067 & 0,07993 \\
\hline$A_{1}$ & 0,04186 & 0,05378 & 0,05995 \\
\hline$A_{2}$ & 0,04186 & 0,02689 & 0,01998 \\
\hline$A_{3}$ & 0,29065 & 0,32147 & 0,32231 \\
\hline$A_{4}$ & 0,19249 & 0,16468 & 0,16458 \\
\hline$A_{5}$ & 0,12290 & 0,12291 & 0,12291 \\
\hline$A_{6}$ & 0,11774 & 0,11776 & 0,11776 \\
\hline$A_{7}$ & 0,19249 & 0,19251 & 0,19251 \\
\hline$\sum_{j=1}^{7} A_{j}$ & 1,00000 & 1,00000 & 1,00000 \\
\hline
\end{tabular}

Table 5. The optimum grading of the designed asphalt concrete mixture

\begin{tabular}{|c|c|c|c|c|c|}
\hline $\begin{array}{c}\text { Size of } \\
\text { laborato- } \\
\text { ry screen } \\
\text { mesh } \\
d_{i} \mathrm{~mm}\end{array}$ & $\begin{array}{c}\text { Lower and } \\
\text { upper } \\
\text { normalized } \\
\text { values of } \\
\text { asphalt } \\
\text { concrete } \\
\text { mixture } \\
0 / 16 \mathrm{~S}-\mathrm{V}\end{array}$ & $\begin{array}{c}\text { Interval } \\
\text { mean }\end{array}$ & \multicolumn{3}{|c|}{$\begin{array}{c}\text { Cumulative residue on } \\
\text { laboratory screens } \% \\
\text { when ratio of imported } \\
\text { fillers and reclaimed } \\
\text { dust is selected }\end{array}$} \\
\hline & 100 & 100 & 99,83 & 99,83 & 99,83 \\
\hline 22,4 & $90-100$ & 95 & 99,49 & 99,49 & 99,49 \\
\hline 16 & $71-85$ & 78 & 81,57 & 81,57 & 81,57 \\
\hline 11,2 & $60-75$ & 67,5 & 70,21 & 70,22 & 70,22 \\
\hline 8 & $50-62$ & 56 & 57,65 & 57,77 & 57,77 \\
\hline 5 & $35-45$ & 40 & 38,30 & 40,42 & 40,42 \\
\hline 2 & $21-35$ & 28 & 29,94 & 31,78 & 31,77 \\
\hline 0,71 & $11-25$ & 18 & 18,45 & 19,21 & 19,17 \\
\hline 0,25 & $6-10$ & 8 & 7,91 & 7,77 & 7,66 \\
\hline 0,09 & & & & & \multicolumn{3}{|c|}{} \\
\hline
\end{tabular}

\section{Conclusions}

1. Since the methods of quality control and regulation of asphalt concrete mixture production are not perfect yet, very often the products do not comply with the requirements stipulated in Standards, Regulations and

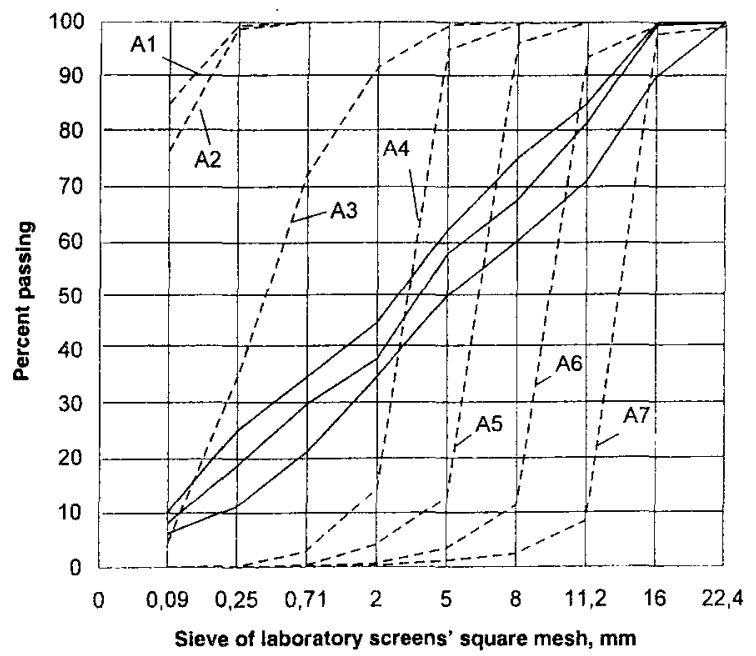

Fig 2. The normalized curves of optimum grading of asphalt concrete mixture $0 / 16 \mathrm{~S}-\mathrm{V}$ and designed of 7 aggregates with $\lambda=1$ of wearing course

Work Instructions. Beside mass of continuous batchers which deliver flows and yields of initial cold aggregates, mass of finally batched hot fractions screened through technological screens, cold imported fillers and reclaimed dust portions measured by discrete batchers shall be estimated with reference to the actual grading of these aggregates. Since the grading of aggregates changes, its mass shall be changed as well. It is rational to estimate the best quantities of all aggregates mass by applying conditional optimization mathematical model presented in the work which takes into consideration ratio of imported fillers and reclaimed dust selected in the asphalt concrete mixture production technology.

2. Synthesis of mathematical optimization theory and technological process of asphalt concrete mixture production enabled to solve the problem of asphalt concrete mixture production quality both theoretically and practically by applying the new methodology of required mass estimation of aggregates measured by asphalt concrete plant discrete batchers as well as its practical implementation algorithm.

3. To optimize the quantity of aggregates, the criterion of the least deflections squares between normalized and calculated asphalt concrete mixture mineral part grading of partial sieve residues on laboratory screens was applied. Therefore, when solving this optimization task, only one best quantity of used aggregates in the mixture which complies with this criterion is obtained.

4. The presented algorithm is original and new and:

- enables to use all available materials in the production of the mixture. Having evaluated the actual grading of aggregates hot screened fractions according to the laboratory tests, the mass ratio of imported fillers and reclaimed dust is estimated efficiently and precisely. Therefore, asphalt concrete mixture which complies with the requirements stipulated in composition design and Regulations DAT.AD-96 is produced best; 
- enables to apply the requirements of normalized asphalt concrete mixture production technology since the necessity has been substantiated and the selected ratio of cold imported fillers (IF) $A_{1}$ and reclaimed dust (RD) which settled on dry air purification equipment and accumulated in the reservoir of asphalt concrete plant returning dust $A_{2}$ has been taken into consideration for the first time;

- is easily applied in practice since at the end of each working day, Head, Technology Director or Head of Laboratory of asphalt concrete mixture production can immediately calculate the required ratio of materials mass on PC based on the laboratory data on hot fractions grading (quality of screening) according to the presented new methodology, algorithm and programme, and an operator of an asphalt concrete plant can appropriately adjust the position of batches fixing hands or asphalt concrete plant computer management programme.

5. The mathematical model and algorithm can be applied when improving the Instructions on Asphalt Concrete Production DI-04 2235248.01:1999 of Construction Regulations or when constructing upgraded universal asphalt concrete mixture production quality control methodology in an asphalt concrete plant.

\section{Literature}

1. Acceptance procedures of works of construction of roads. Asphalt concrete coverings. DAT. AD-96 with corrections and additions 1999 release. (Automobiliu keliu tiesimo darbų prièmimo taisyklès. Asfaltbetonio dangos DAT. AD-96). Vilnius: The state enterprise „Problematika“. 1999. 78 p. (in Lithuanian).

2. Koroliov I. V. Ways of economy of bitumen in road construction. (Пути экономии в дорожном строительстве). Moscow: Transport, 1986. 149 p. (in Russian).

3. Vislavičius K. General principles of modelling physicalmechanical properties of conglomerates. Civil Engineering (Statyba). Vilnius: Technika, 2000, Vol VI, No 3, p. 175-178 (in Lithuanian).

4. Ribjev I. A. Asphalt concrete (Асфальтовые бетоны). Moscow: Visšaja škola, 1969. 400 p. (in Russian).

5. The investigation of the effect of the precision and stability of technological processes taking place in asphalt concrete plant on mix quality. Interim report. Contract No 258/ 86-MA. Supervisor H. Sivilevičius. VGTU. Vilnius, 2001. 165 p. (in Lithuanian).

6. Yemen I. The design of asphaltic concrete using mathematical models and linear programming techniques. Austral. Road Res. Board Proc 5th Conf., Canbera, 1970, Vol 5, Part 5, Melburn, p. 248-265.

7. Jordan P. G., Thomas M. E. Prediction of cooling curves for hot-mix paving materials by a computer program. Transport Research Laboratory, Crawthorne, 1976, LR 729.

8. Lesage I. Grading computer analysis of asphalt concrete mixture coat formula. The Bulletin of Interrelation between the Bridges and Road Construction Laboratories. (Bulle- tin de liaison des laboratoires des ponts et chaussees). Jan - Febr, 1977, No 87, p. 59-67 (in France).

9. Nikolova V., Bojadžijev V. Use of a method of the least squares at selection of a curve of optimum grading. Rouds (Птиша), 1985, 24, No 2, p. 17-19 (in Bulgarian).

10. Mullner A., Pilz P. Theoretical substantiation of designing of asphalt concrete and cement concrete grading. Street (Strasse), 1987, 27, No 2, p. 54-55 (in German).

11. Aljassar A., Hass R. Toward automating size-gradation analysis of mineral aggregate. Transportation Research Record 1437. Transportation Research Board, National Research Council. Washington, D.C., 1994, p. 35-42.

12. Strazdas R., Sivilevičius H. Optimization of required quantity of mineral components of asphalt concrete mixture. In: Proceedings of the Conference of Young Lithuanian Scientists "Lithuania without science is Lithuania without the future". Transport, held in Vilnius on 24 May (Lietuvos jaunuju mokslininku konferencijos „Lietuva be mokslo Lietuva be ateities", ivykusios Vilniuje $2000 \mathrm{~m}$. gegužès mèn. 24 d., medžiaga). Vilnius: Technika, 2000, p. 88--94 (in Lithuanian).

13. Sivilevičius $H$. The analysis and quality estimation of asphalt concrete mixers used in Lithuania. City development and roads Supplement of journal "Civil Engineering". (Miesto plétra ir keliai. Mokslo žurnalo „Statyba" priedas). Vilnius: Technika, 2000. p. 60-71 (in Lithuanian).

14. Bitominous mixtures in road construction / Edited by Dr. Hunter R. N. London Thomas Telford. 1997. 441 p.

15. Poradek S. V. Once more on the dust collectors for asphalt concrete plants. Science and Engineering in road area. (Наука и техника в дорожной отрасли), 2001, No 1 (16), p. 19-20 (in Russian).

16. Sivilevičius $H$. Research of the technology factors influencing quality of mineral materials bolting in paving plants. In: Questions of creation and introduction of new designs and technologies of building-road machines. (Вопросы создания и внедрения новьг конструкций и технологий строительно-дорожных машин). Vilnius, 1990, p. 46-55 (in Russian).

17. Poljakov A. B., Poradek S. V. What the screen for asphalt mixing plants. Science and Engineering in road area. (Наука и техника в дорожной отрасли). 1999, № 2 (9), p. 28-29 (in Russian).

18. The instruction of production of asphalt concrete. The working instruction DI-04 / The general works of roads building and repairing. In: Building rules ST 2235248. 01 . (Asfaltbetonio gamybos proceso instrukcija). Vilnius: Association „Lietuvos keliai“", 1999, p. 119-139 (in Lithuanian).

19. Aladjev V. Z., Bogdevičius M. A. Interactive Maple: Solution of the Mathematical, Statistical and Engineeringphysical Problems. Tallinn-Vilnius: International Academy of Noosphere, 2001, CD-RO ISBN 9985-9277-1-0.

20. Aladjev V. Z., Bogdevičius M. A. Maple 6. Solution of the Mathematical, Statistical and Engineering-physical Problems. (Maple 6: Решение математических, статистических и инженерно-физических задач). Moscow: Laboratory of Basic Knowledges, 2001. 824 p. (in Russian). 